\title{
Abatement of ozone-recalcitrant micropollutants during municipal wastewater ozonation: kinetic modelling and surrogate-based control strategies
}

Alberto Cruz-Alcalde*, Santiago Esplugas, Carme Sans

Department of Chemical Engineering and Analytical Chemistry, Faculty of Chemistry, Universitat de Barcelona, C/Martí i Franqués 1, 08028 Barcelona, Spain

*Corresponding author: alberto.cruz@ub.edu

\section{ABSTRACT}

Although ozonation is nowadays recognized as one of the most efficient technologies for micropollutants abatement in municipal wastewater effluents, several of the compounds potentially present in those waters exhibit a strong resistance to direct ozone oxidation. In addition, the real-time control of the removal process is still challenging. In this work, the abatement of ozone-recalcitrant micropollutants during wastewater ozonation of six different wastewater effluents was explored using the pesticide acetamiprid as hydroxyl radical $(\bullet \mathrm{OH})$ probe. By means of this data, the oxidation efficiency (i.e., hydroxyl radical exposure per consumed ozone) could be described by means of a two-stage model based on the $\mathrm{ROHO}_{\mathrm{O}}$ concept. This was possible using a semi-continuous bubbling ozone contactor in all experiments, which permitted the inclusion of the ozone mass balance in the model. RОНОз values of $(1.53-7.60) \cdot 10^{-7} \mathrm{~s}$ for initial ozonation stage and (0.61$2.95) \cdot 10^{-6} \mathrm{~s}$ for the secondary stage were obtained allowing the characterization and comparison of the process performance in a wide range of effluent qualities, including 
water matrices with a high content of dissolved and particulate organic matter (total organic carbon (TOC), dissolved organic carbon (DOC) and turbidity tested ranges: 6.7$50 \mathrm{mg} \mathrm{C} \mathrm{L}{ }^{-1}, 6.6-27.6 \mathrm{mg} \mathrm{C} \mathrm{L}^{-1}$ and 0.3-28.6 NTU, respectively). Finally, a surrogate strategy involving $\cdot \mathrm{OH}$ exposure estimation by means of ultraviolet absorbance at 254 nm (UVA 254$)$ measurements was proposed based on the $R_{O H O 3}$ concept, and by means of its application the removal of atrazine and ibuprofen in six different wastewaters could be rightly predicted $\left(\mathrm{R}^{2}>0.98\right)$.

\section{KEYWORDS}

Wastewater ozonation, $\mathrm{O}_{3}$-resistant micropollutants, $\bullet \mathrm{OH}$ exposure, $\mathrm{R}_{\mathrm{OHO}}$ concept, $\mathrm{UVA}_{254}$, Surrogates

\section{Introduction}

Ozonation has largely demonstrated to be one of the most effective and easily implementable advanced treatment technologies for micropollutants (MPs) abatement in municipal wastewater effluents. From laboratory to full-scale studies, a considerable number of works have reported the benefits, in terms of water quality, derived from ozone $\left(\mathrm{O}_{3}\right)$ application after the secondary stage of a wastewater treatment train (Bourgin et al., 2018; Gerrity et al., 2011; Nakada et al., 2007; Reungoat et al., 2012; Zimmermann et al., 2011). However, and although this technology is nowadays increasingly implemented in wastewater treatment plants (WWTPs) around the world (Chys et al., 2017), the control of MPs removal during the process - necessary to optimize the required oxidant doses is still challenging. Despite the vast advances in chromatographic techniques, which 
currently allow the simultaneous determination of a few hundred compounds from $\mu \mathrm{g} \mathrm{L}-$ ${ }^{1}$ to ng L ${ }^{-1}$ levels (Bourgin et al., 2018), the huge number of chemicals (Drewes et al., 2013; Oulton et al., 2010) potentially present in wastewater effluents makes the measurement of their individual oxidation efficiencies a completely prohibitive option from a practical and economical perspective. A helpful alternative could be the employment of chemical kinetics, which establishes that the removal of any MP during ozonation can be predicted if the second-order rate constants of reactions between this compound and both ozone ( $\left.\mathrm{k}_{\mathrm{O} 3}\right)$ and hydroxyl radicals $(\mathrm{k} \cdot \mathrm{OH})$, as well as the ozone and hydroxyl radical exposures $\left(\int[\mathrm{O} 3] \mathrm{d} t\right.$ and $\left.\int[\cdot \mathrm{OH}] \mathrm{d} t\right)$ are known, according to Eq. 1 .

$$
-\ln \left(\frac{[M P]}{[M P]_{0}}\right)=k_{O_{3}} \int\left[O_{3}\right] \mathrm{d} t+k_{\bullet O H} \int[\bullet O H] \mathrm{d} t
$$

Despite the great potential of ozonation process, some of the organic compounds typically present in secondary effluents present a strong recalcitrance towards direct ozone oxidation. They are known as ozone-resistant micropollutants, and they are characterized by second-order rate constants with molecular ozone generally below $10 \mathrm{M}^{-1} \mathrm{~s}^{-1}$ (Lee et al., 2013). As most of these chemicals are only effectively eliminated by hydroxyl radical $(\bullet \mathrm{OH})$ oxidation, they are considered to be one of the main limiting factors for ozone applications (Schindler Wildhaber et al., 2015). In some parts of the world, obtaining a high quality water from wastewater may be required in a near future for applications involving further human exposure. In these situations, the monitoring and control of the fate of ozone-recalcitrant MPs during ozonation might be essential, especially considering that some of these compounds can pose risks to human and environmental health. In such cases, and according to chemical kinetics (see Eq. 1), if these species (ozone-resistant compounds) are effectively removed from the effluent, it can be fairly 
hypothesized that those other compounds presenting a certain degree of reactivity with $\mathrm{O}_{3}$ (i.e., in general, $\mathrm{k}_{03}$ values larger than $10 \mathrm{M}^{-1} \mathrm{~s}^{-1}$ ) would be faster oxidized. It is clear, therefore, that a potential approach to ensure the removal of MPs during the ozonation step in a WWTP could be the control of those MPs whose abatement is more difficult to achieve, that is, $\mathrm{O}_{3}$-resistant compounds. In accordance with this hypothesis of work, Eq. 1 could be simplified to Eq. 2 .

$$
-\ln \left(\frac{[M P]}{[M P]_{0}}\right)=k_{\bullet O H} \int[\bullet O H] \mathrm{d} t
$$

Regarding $k_{\bullet} \mathrm{OH}$ values, there is a large kinetic database in literature for reactions between organic compounds and hydroxyl radicals (Buxton et al., 1988; von Sonntag and von Gunten, 2012). With respect to $\bullet \mathrm{OH}$ exposure, this term can be experimentally determined through the monitoring of a $\bullet \mathrm{OH}$ probe compound (Elovitz and Von Gunten, 1999). This method, although useful for prediction of contaminants removal in lab-scale studies or during the planning stage of wastewater ozonation units (Lee et al., 2014, 2013; Schindler Wildhaber et al., 2015), is time consuming and hardly has an application in real-time control systems. A possible solution to this limitation could be the use of a water quality parameter as surrogate for online estimation of $\bullet \mathrm{OH}$ exposure. A recent work by Chys and coworkers shows the potential of this approach employing the ultraviolet absorbance at $254 \mathrm{~nm}\left(\mathrm{UVA}_{254}\right)$ and total fluorescence (TF) as surrogates (Chys et al., 2017). In a parallel - but related - line of work, some studies have also shown that decreases in $\mathrm{UVA}_{254}$ and total fluorescence (TF) could be correlated to the abatement of micropollutants (Gerrity et al., 2012; Park et al., 2017; Stapf et al., 2016). 
In general, lab-scale studies dealing with micropollutants oxidative abatement from wastewater by means of ozonation - and especially those working on the kinetic modelling of the process - ignore the ozone mass transfer and the relationship between this factor and the process performance. The performance of batch ozonation experiments with addition of $\mathrm{O}_{3}$ from aqueous stock solutions, although practical for absolute kinetics determinations, prevents the accurate characterization of the initial, fast $\mathrm{O}_{3}$-consuming, ozonation stage. Furthermore, in most ozonation studies the oxidation performance is usually described by means of parameters that are strongly dependent from the applied dose of oxidant, such as the $R_{c t}$ concept (Elovitz and Von Gunten, 1999). Regarding this, Kwon and coworkers (Kwon et al., 2017) have recently proposed the RОНОз concept, a kinetic parameter defined as the $\bullet \mathrm{OH}$ exposure (i.e., the time-integrated $\bullet \mathrm{OH}$ concentration) per consumed $\mathrm{O}_{3}$ (i.e., the transferred ozone dose (TOD)) (see Eq. 3). The $R_{\mathrm{OHO}}$ concept is independent from the $\mathrm{O}_{3}$ dose and appears to be useful for both, performance characterization and kinetic modelling of ozonation process. However, a

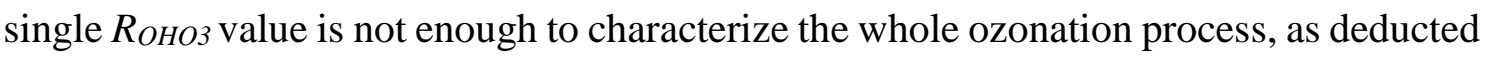
by the work performed by Kwon et al. (Kwon et al., 2017).

$$
R_{\mathrm{OHO}_{3}}=\frac{\int[\bullet \mathrm{OH}] \mathrm{d} t}{\mathrm{TOD}}
$$

The main goal of this study was, on one hand, to assess the oxidation performance of semi-continuous ozonation for enhanced wastewater treatment, particularly focusing on the monitoring and control of ozone-resistant micropollutants removal from effluents. On the other, and by means of kinetic parameters like $\mathrm{ROHO}_{O}$ and the monitoring of $\mathrm{UVA}_{254}$ as surrogate quality parameter, to establish the fundamentals of potential strategies for the real-time prediction and control of the abatement of these recalcitrant species during 
the whole process. The proposed models were validated by predicting the abatement of ozone-recalcitrant micropollutants atrazine and ibuprofen in all the employed effluents. The removal of moderate and highly ozone-sensitive micropollutants during the process was also verified.

\section{Materials and methods}

\subsection{Chemicals and reagents}

Acetamiprid (ACMP), atrazine (ATZ), ibuprofen (IBU), methiocarb (MC) and dichlorvos (DDVP) analytical standards were acquired from Sigma-Aldrich (Germany). Ultrapure water was produced by a filtration system (Millipore, USA). Pure oxygen ( $\geq 99.999 \%$ ) was supplied by Abelló Linde (Spain).

\subsection{Wastewater effluents}

Six wastewater effluents from five WWTPs in the province of Barcelona (Spain) were employed in this work. Three of them (M-VAC, M-VAL and M-GAV) came from membrane biological reactor (MBR) systems, whereas the rest (C-PRA, C-GAV and CC-LLA) were collected from conventional activated sludge (CAS) treatments. All samples were directly collected from the outlet stream of the corresponding biological treatments. Their main quality parameters are gathered in Table 1 . The raw CAS effluents were filtered with conventional filter paper to remove the largest particles. For each sample, total organic carbon (TOC) and dissolved organic carbon (DOC) (after being filtered through $0.45 \mu \mathrm{m}$ PTFE syringe filters) were measured by means of a Shimadzu 
TOC-VCSN analyzer. The ultraviolet (UV) absorbance was determined with a DR6000 UV VIS spectrophotometer (Hach, USA). Turbidity was measured with a 2100Q portable turbidimeter, also by Hach. Alkalinity was determined by means of an automatic titration device coupled with a $\mathrm{pH}$ meter (Crison, Spain). Nitrite $\left(\mathrm{NO}_{2}{ }^{-}\right)$concentration was determined through ion-exchange chromatograph with UV detection. All the effluent samples were stored at $4{ }^{\circ} \mathrm{C}$ prior to be used.

Table 1. Main effluent water quality parameters (M-: membrane biological systems; C-: conventional activated sludge treatments). All measurements were performed per triplicate. Discrepancies between values were in all cases lower than $5 \%$.

\begin{tabular}{|c|c|c|c|c|c|c|c|c|}
\hline $\begin{array}{c}\text { WWTP } \\
\text { ID }\end{array}$ & Location & pH & $\begin{array}{c}\text { TOC } \\
{\left[\mathrm{mg} \mathrm{C} \mathrm{L}^{-1}\right]}\end{array}$ & $\begin{array}{c}\text { DOC } \\
{\left[\mathrm{mg} \mathrm{C} \mathrm{L}^{-1}\right]}\end{array}$ & $\begin{array}{l}\mathbf{U V}_{254} \\
{\left[\mathrm{~cm}^{-1}\right]}\end{array}$ & $\begin{array}{c}\text { Turbidity } \\
\text { [NTU] }\end{array}$ & $\begin{array}{c}\text { Alkalinity } \\
{\left[\mathrm{mg} \mathrm{CaCO}_{3} \mathrm{~L}^{-1}\right]}\end{array}$ & $\begin{array}{c}\mathrm{NO}_{2}^{-} \\
{\left[\mathrm{mg} \mathrm{N} \mathrm{L}^{-1}\right]}\end{array}$ \\
\hline M-VAC & Vacarisses & 7.9 & 6.7 & 6.6 & 0.179 & 0.6 & 330 & 0.85 \\
\hline M-VAL & Vallvidrera & 7.4 & 10.5 & 10.3 & 0.163 & 0.9 & 178 & 0.03 \\
\hline M-GAV & $\begin{array}{c}\text { Gavà- } \\
\text { Viladecans }\end{array}$ & 7.7 & 12.4 & 12.1 & 0.149 & 0.3 & 200 & 0.12 \\
\hline C-PRA & $\begin{array}{l}\text { El Prat de } \\
\text { Llobregat }\end{array}$ & 7.5 & 14.0 & 13.6 & 0.229 & 1.1 & 264 & 0.09 \\
\hline C-GAV & $\begin{array}{c}\text { Gavà- } \\
\text { Viladecans }\end{array}$ & 7.8 & 42.1 & 27.6 & 0.672 & 28.6 & 517 & 0.09 \\
\hline C-LLA & La Llagosta & 7.7 & 25.6 & 21.3 & 0.664 & 20.1 & 419 & 0.03 \\
\hline
\end{tabular}

The employed wastewater effluents showed broad variations in their main quality parameters. These marked differences were considered highly valuable since allowed the performance of a study whose results could cover a wide range of water qualities. 


\subsection{Ozonation of wastewater effluents}

Wastewater ozonation experiments were performed in a $750 \mathrm{~mL}$ jacketed reactor, operated in semi-continuous mode. Ozone was produced by a 301.19 lab ozonizer (Sander, Germany) and injected at the bottom of the reactor by means of a porous diffuser made of sintered glass (pore size: $150-250 \mu \mathrm{m}$ ). A mechanical mixing system ensured the good contact between liquid and gas phases. Experiments were performed at $20 \pm 1{ }^{\circ} \mathrm{C}$, without $\mathrm{pH}$ adjustment. The gas flow rate and the inlet ozone concentration were maintained at $0.1 \mathrm{NL} \mathrm{min}^{-1}$ and $30 \mathrm{mg} \mathrm{NL}^{-1}$, respectively. Inlet and outlet gas-phase ozone concentrations were continuously monitored by two BMT 964 ozone analyzers (BMT Messtechnik, Germany) placed up and downstream the reactor, respectively. The ozone concentration in the aqueous phase was measured by means of a $\mathrm{Q} 45 \mathrm{H} / 64$ dissolved $\mathrm{O}_{3}$ probe (Analytical Technology, USA), which was connected to a liquid recirculation stream (flow rate: $200 \mathrm{~mL} \mathrm{~min}^{-1}$ ). A detailed scheme of the ozonation setup is shown in Fig. 1.

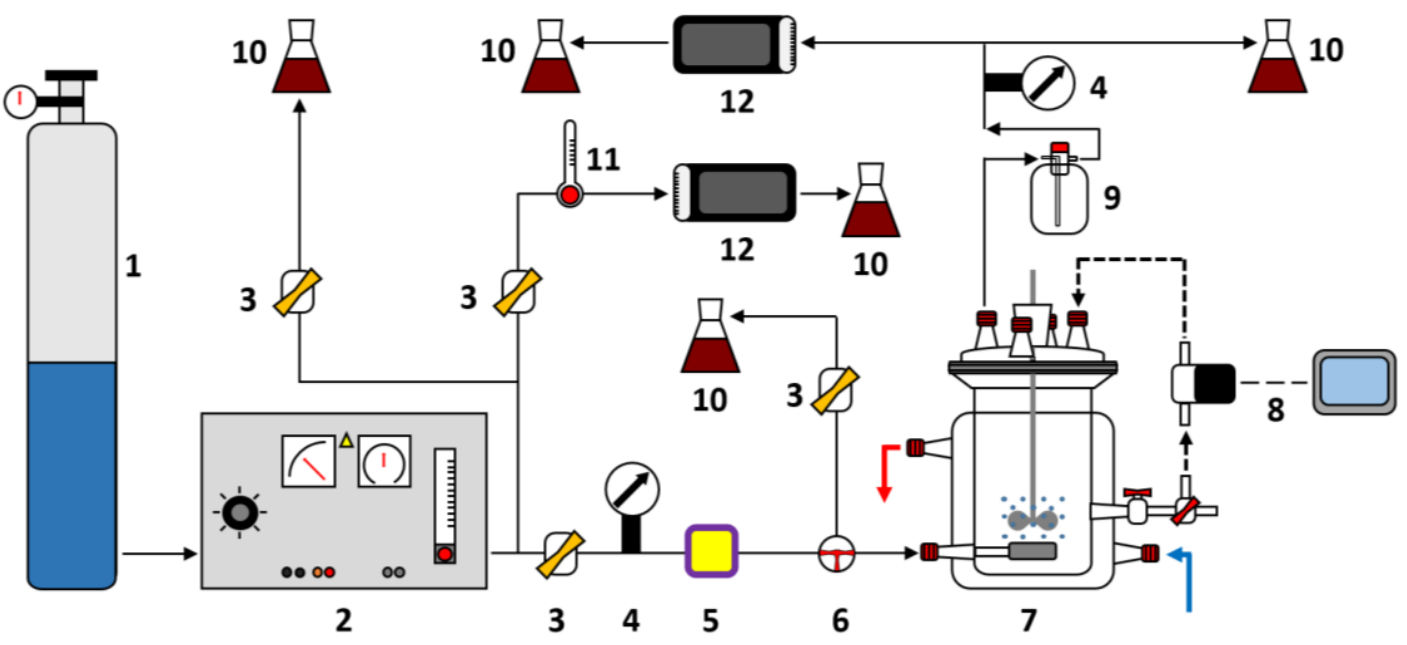


Figure 1. Ozonation setup. 1. Oxygen bottle; 2. Ozonizer; 3. Regulating valve; 4. Manometer; 5. Gas flowmeter; 6. Three-way valve; 7. Reactor; 8. Dissolved ozone measuring system; 9. Foam trap; 10. KI solution for $\mathrm{O}_{3}$ quenching; 11. Thermometer; 12 . Ozone analyzer (gas-phase).

The ozone consumption was determined as the transferred ozone dose (TOD), which is defined by Eq. 4 and represents the accumulated amount of ozone that is transferred to the water sample per unit of volume and time.

$$
T O D=\int_{0}^{t} \frac{F_{g a s}}{V_{l i q}} \cdot\left(\left[O_{3}\right]_{g a s, \text { in }}-\left[O_{3}\right]_{\text {gas }, \text { out }}\right) \cdot \mathrm{d} t
$$

$F_{\text {gas }}, V_{\text {liq }}$ are the gas flow rate and the liquid volume, respectively; $t$ stands for the ozonation time; $\left[\mathrm{O}_{3}\right]_{\text {gas, in }}$ and $\left[\mathrm{O}_{3}\right]_{\text {gas, out }}$ represent the ozone concentrations measured at the inlet and outlet gas streams, respectively. The trapezoidal method of numerical integration (integration step: $10 \mathrm{~s}$ ) was employed in these calculations. The existent dead volume between the reactor liquid-gas interface and the outlet ozone gas analyzer was considered for TOD calculations. The reactor headspace was modelled as a continuous stirred-tank reactor (CSTR) to account for ozone dilution in the gas phase, whereas gas streams circulating through standard polytetrafluoroethylene (PTFE) tubing have been considered to follow plug-flow behavior (estimated delay: $2.0 \mathrm{~min}$ ).

Each wastewater effluent was spiked with $100 \mu \mathrm{g} \mathrm{L}{ }^{-1}$ of ACMP as $\bullet O H$ probe compound $\left(k_{A C M P, O 3}=0.25 \mathrm{M}^{-1} \mathrm{~s}^{-1}\right.$ and $k_{A C M P,} \cdot O H=2.1 \cdot 10^{9} \mathrm{M}^{-1} \mathrm{~s}^{-1}($ Cruz-Alcalde et al., 2017a) $)$, then ozonized for $60 \mathrm{~min}$ under the mentioned operational conditions. Samples were withdrawn at known time intervals and kept at room conditions until complete consumption of dissolved ozone was achieved. The residual concentration of ACMP was 
then measured by high performance liquid chromatography with UV detection (HPLCUV). The UV absorbance data was determined with a DR6000 UV-Visible spectrophotometer (Hach, USA). Additional ozonation experiments were performed in order to test the proposed strategy for the control of micropollutants abatement. In this case, each wastewater effluent was spiked with low concentrations $\left(25-50 \mu \mathrm{g} \mathrm{L}^{-1}\right)$ of the pesticides atrazine (ATZ), methiocarb (MC) and dichlorvos (DDVP), as well as the antiinflammatory drug ibuprofen (IBU). The residual concentrations of these micropollutants in samples taken at various reaction times were also determined by HPLC-UV. All experiments were performed in duplicate.

The concentrations of ACMP, ATZ, MC, DDVP and IBU were quantified by means of a HPLC equipped with a diode array detector (DAD), all supplied by Agilent (1260 Infinity). The column employed was a Teknokroma Mediterranea Sea18 (250 mm x 4.6 $\mathrm{mm}$ and $5 \mu \mathrm{m}$ size packing). The flow rate and injection volume were set, respectively, at $1.0 \mathrm{~mL} \mathrm{~min}{ }^{-1}$ and $100 \mu \mathrm{L}$ in all determinations. For ACMP and DDVP analyses, the mobile phase consisted of 30:70 volumetric mixtures of acetonitrile and Milli-Q water acidified at $\mathrm{pH} 3$ by the addition of $\mathrm{H}_{3} \mathrm{PO}_{4}$. The detection wavelength was set to $250 \mathrm{~nm}$ (ACMP) and 225 (DDVP) nm, respectively. For ATZ, MC and IBU quantification, the mobile phase consisted of 70:30 volumetric mixtures of acetonitrile and $\mathrm{pH} 3$ Milli-Q water, and the UV detection was performed at $225 \mathrm{~nm}$. The limits of quantitation were: $3.3 \mu \mathrm{g} / \mathrm{L}$ (ACMP), $9.2 \mu \mathrm{g} / \mathrm{L}$ (DDVP), $0.9 \mu \mathrm{g} / \mathrm{L}$ (ATZ), $8.3 \mu \mathrm{g} / \mathrm{L}$ (MC) and $2.1 \mu \mathrm{g} / \mathrm{L}$ (IBU).

\section{Results and discussion}




\subsection{Ozone mass transfer and demand}

During wastewater ozonation experiments, inlet and outlet (gas phase), as well as dissolved (liquid phase) ozone concentrations were continuously measured and registered (see Fig. S1 of the Supplementary Information (SI)). The monitoring of these data allowed a complete assessment of the ozone mass balance and the estimation of some parameters describing key aspects of the process, such as the ozone transfer efficiency $\left(\eta_{t r}\right)$, the volumetric mass transfer coefficient $\left(K_{L} a\right)$, the rate of ozone decay $\left(k_{d}\right)$ and the immediate ozone demand (IOD). The corresponding values for each effluent are gathered in Table 2. Further information regarding these parameters and their estimation procedures can be found in the SI (Texts S1-S3 and Figs. S2-S5).

Table 2. IOD, $k_{d}$ and $\eta_{t r}$ values determined for wastewater effluent samples.

\begin{tabular}{|c|c|c|c|c|c|}
\hline $\begin{array}{c}\text { Sample } \\
\text { ID }\end{array}$ & $\begin{array}{c}\text { IOD } \\
{\left[\mathrm{mg} \mathrm{O}_{3} \mathrm{~L}^{-1}\right]}\end{array}$ & $\begin{array}{c}\mathbf{k}_{\mathbf{d}} \\
{\left[\mathrm{min}^{-1}\right]}\end{array}$ & $\begin{array}{c}\mathrm{K}_{\mathrm{L}} \mathbf{a} \\
{\left[\mathrm{min}^{-1}\right]}\end{array}$ & $\begin{array}{c}\eta_{\text {tr }}, 1^{\text {st }} \text {-phase } \\
{\left[\operatorname{tr} . O_{3} / \text { app. } O_{3}\right]}\end{array}$ & $\begin{array}{c}\eta_{\text {tr }}, 2^{\text {nd }} \text {-phase } \\
{\left[\operatorname{tr} . O_{3} / \text { app. } O_{3}\right]}\end{array}$ \\
\hline M-VAC & 14 & 0.170 & 0.451 & 0.705 & 0.115 \\
\hline M-VAL & 9 & 0.175 & 0.389 & 0.771 & 0.121 \\
\hline M-GAV & 11 & 0.181 & 0.396 & 0.742 & 0.141 \\
\hline C-PRA & 16 & 0.221 & 0.397 & 0.725 & 0.154 \\
\hline C-GAV & 28 & 0.621 & 0.210 & 0.853 & 0.247 \\
\hline C-LLA & 19 & 0.582 & 0.228 & 0.840 & 0.233 \\
\hline
\end{tabular}

Differences observed between effluents in ozone transfer behavior could be explained by the properties of each sample, especially - but not exclusively - the initial concentrations of dissolved and particulate organic matter (OM) (see TOC and DOC data in Table 1). 
This is clearly illustrated by results obtained for IOD. This parameter describes the ozone demand at the initial stage of ozonation, where this oxidant is instantaneously consumed by the reactive components of the water matrix. Thus, this parameter represents the dose of ozone for which the transition between primary (fast) and secondary (slow) ozonation stages takes place. In general, increasing contents in organic matter leads to larger ozone demands. DOC-normalized IODs (i.e., IOD/DOC) were in general in the range between 0.9 and $1.2 \mathrm{mg} \mathrm{O}_{3} \mathrm{mg} \mathrm{C}^{-1}$, being this a proof of the similar effluent organic matter (EfOM) character and ozone needs for different effluent sources. The only exception was found to be the M-VAC sample, which presented an IOD/TOC of 1.7 (ozone demand exerted by nitrite (Naumov et al., 2010) already deducted). This particular result could be probably attributed to the also individual properties of that effluent - besides nitrite content: highest $\mathrm{pH}$, high alkalinity, and one of the highest $\mathrm{UVA}_{254} / \mathrm{DOC}$ ratios. For the rest of parameters gathered in Table 2, in general, the relationship between ozone transfer and effluent quality observed in the present study was in agreement with previous findings and fundamental concepts (Jiang et al., 2009; Levenspiel, 1999; Marce et al., 2016).

\subsection{Removal of a model ozone-resistant micropollutant and determination of $\mathrm{ROH}_{\mathrm{O}, \mathrm{O}}$ values}

Fig. 2 shows ACMP degradation evolution during ozonation experiments as a function of the employed $\mathrm{O}_{3}$ :DOC ratios (determined as TOD/initial DOC). Ozonation was extended to applied ozone doses significantly higher than that reported in related lab-, pilot- and full-scale ozonation works, where $\mathrm{O}_{3}$ :DOC ratios mainly between 0.5 and $1.5 \mathrm{mg} \mathrm{O} 3 \mathrm{mg}$ $\mathrm{C}^{-1}$ but up to $2 \mathrm{mg} \mathrm{O}_{3} \mathrm{mg} \mathrm{C}^{-1}$ (Bourgin et al., 2018; Chys et al., 2017; Gerrity et al., 2011; Kwon et al., 2017; Lee et al., 2013) have been employed. Typical conditions applied in 
actual ozonation units are characterized by none or limited ozone residual in the aqueous phase during the process, that is, working within the initial ozonation stage in which all the applied ozone is instantaneously consumed, before IOD completion. In Fig. 2, the maximum and minimum DOC-normalized IOD values (IOD/DOC) determined during experimentation are represented by dashed lines.

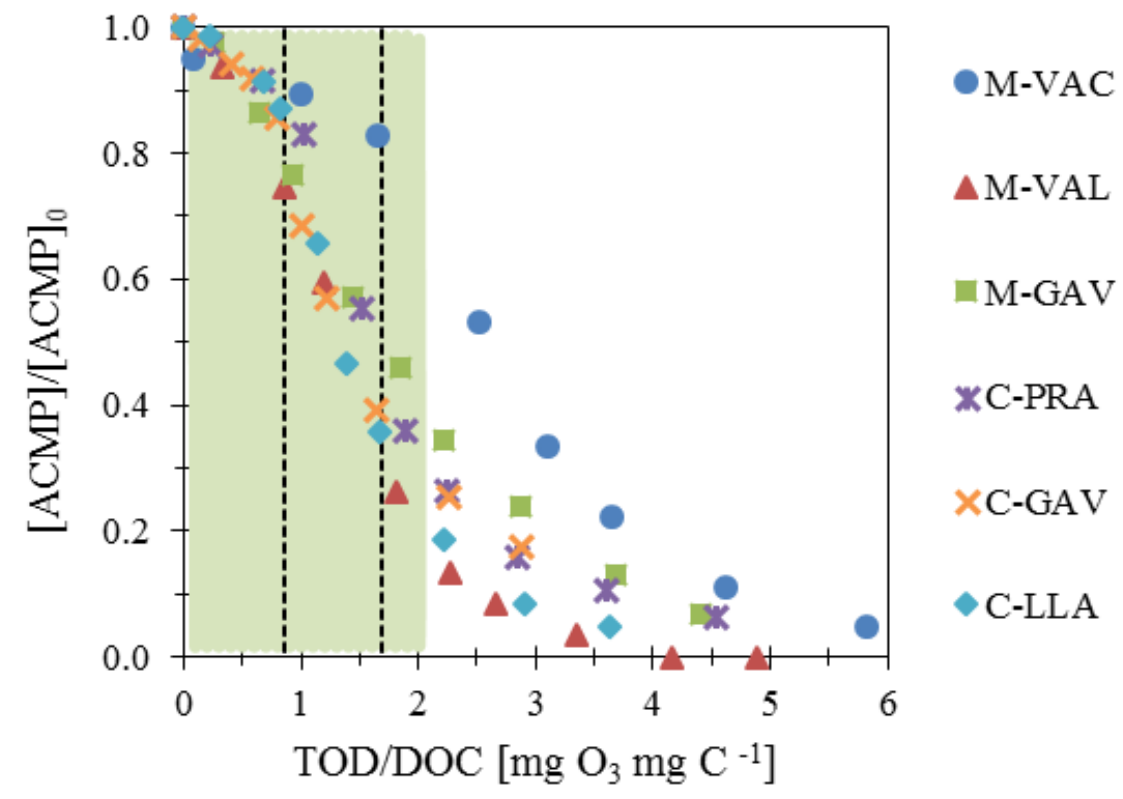

Figure 2. Abatement of acetamiprid from different wastewater effluents during ozonation, as a function of the TOD/DOC ratio. The shaded area represents the typical range of $\mathrm{O}_{3}$ :DOC ratios applied in ozonation studies (up to $2 \mathrm{mg} \mathrm{O}_{3} \mathrm{mg} \mathrm{C}^{-1}$ ). Maximum and minimum DOC-normalized IOD values are also represented by dashed vertical lines.

It is clear, in the view of recent research, that currently employed ozone doses are not able to completely remove ozone-recalcitrant chemicals (Bourgin et al., 2018; Lee et al., 2013). That is also obvious in the view of the findings of the present work, where ACMP removals for a maximum $\mathrm{O}_{3}: \mathrm{DOC}$ ratio of $2 \mathrm{mg} \mathrm{O}_{3} \mathrm{mg} \mathrm{C}^{-1}$ ranged between 30 and $80 \%$, depending on the water source. If ozone was dosed up to IOD completion, the following ACMP degradation levels would be approximately obtained: $17 \%$ for M-VAC, $25 \%$ for 
M-VAL, 22\% for M-GAV; $20 \%$ for C-PRAT; $31 \%$ for C-GAV and 25\% for C-LLA. Definitely, if a significant abatement of ozone-recalcitrant micropollutants is wanted to be reached, ozonation should be extended beyond IOD. However, and due to the high pollution loads (i.e., high DOC) of samples from conventional activated sludge effluents, the absolute doses of oxidant to apply for the abatement of $\mathrm{O}_{3}$-resistant compounds would be considered uneconomical. Thus, for these effluents other alternatives should be explored for the removal of these chemical species from wastewaters. On the contrary, extended ozonation could be considered for clearer effluents, such as the MBR systems employed in this study.

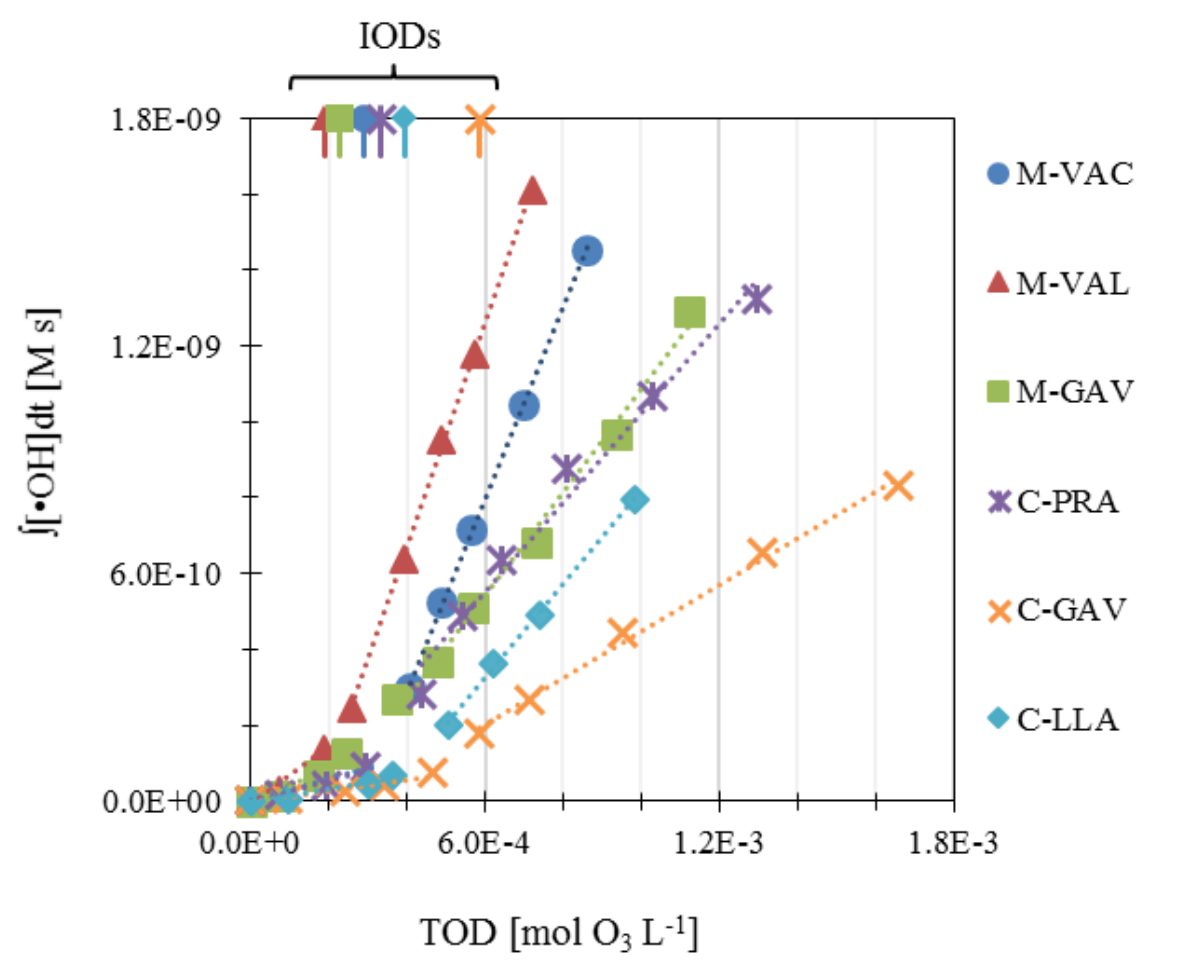

Figure 3. $\int[\bullet \mathrm{OH}] \mathrm{d} t$ versus TOD plot obtained during ozonation of wastewater effluent samples spiked with acetamiprid as $\bullet \mathrm{OH}$ probe compound. The slopes of each linear regression represent the $R_{\text {Оноз values of }}$ primary and secondary ozonation stages, which are gathered in Table 2. $[\mathrm{ACMP}]_{0}=100 \mu \mathrm{g} \mathrm{L}^{-1}$; Gas flow rate $=0.100 \pm 0.005 \mathrm{NL} \mathrm{min}^{-1}$; Inlet (gas) ozone concentration $=30 \pm 1 \mathrm{mg} \mathrm{O}_{3} \mathrm{NL}^{-1} ; \mathrm{T}_{\text {reaction }}=20 \pm 1{ }^{\circ} \mathrm{C}$, $\mathrm{T}_{\text {in }}$ (gas) $=22 \pm 2{ }^{\circ} \mathrm{C} ; \mathrm{P}_{\text {in }}$ (gas) $=25 \pm 2$ mbar. Values of the immediate ozone demand (IOD) for each effluent are marked at the top of the graph and should be read by projecting the symbols on the $\mathrm{x}$-axis. 
Because of the different $\mathrm{O}_{3}$ demands and consumptions according to the individual water qualities (see Table 2 and SI, texts S1-S3 and Figs. S1-S5), the use of $\int[\bullet \mathrm{OH}] \mathrm{d} t$ alone as an absolute indicator of the oxidation performance during ozonation process is not recommended. The $\mathrm{ROHO}_{\mathrm{OH}}$ concept can be used instead. Fig. 3 shows the $\int[\bullet \mathrm{OH}] \mathrm{d} t$ versus TOD (consumed ozone, according to the employed experimental methodology) plot for all the tested effluents. Linear relationships were obtained in all cases $\left(\mathrm{R}^{2}>0.98\right)$ and, according to Eq. 3, the corresponding $\mathrm{ROHO}_{\mathrm{O}}$ values could be determined from their slope values (Table 3). IOD values representing the transition between both stages are also indicated in Fig. 3.

Two different $R_{\mathrm{OHO}}$ were obtained for each water sample, one per each of the two ozone consumption regimes that were observed during ozonation experiments. According to the typically applied conditions in actual ozonation units, first stage $\mathrm{ROHO}_{\mathrm{O}}$ value would be enough to estimate the hydroxyl radical exposure during the treatment. If ozonation is extended beyond IOD with the aim of further removing ozone-recalcitrant species, the secondary $\mathrm{ROHO}_{\mathrm{O}}$ value should be also taken into account. For all effluents, the initial $R_{\mathrm{OHO} 3}$ value was lower than the secondary one. This means that at the beginning of the reaction there were less radicals available per consumed ozone, when there is a strong mass transfer and an instantaneous ozone consumption exerted by $\mathrm{O}_{3}$-reacting matter. After IOD completion, the amount of consumed ozone gradually decreased until stationary conditions were reached. In addition, during the early stage of ozonation the water matrix presents larger amounts of $\bullet \mathrm{OH}$-scavenging matter. This situation changes when the regime switches to the slow phase, as a fraction of these components have already been consumed. From this point, therefore, both the $\mathrm{O}_{3}$ consumption and $\bullet \mathrm{OH}$ scavenging rates diminish. 
Table 3. Summary of $R_{\mathrm{OHO}}, k_{U V A, O 3}$ and $k_{U V A, O H}$ (experimental and determined as $k_{U V A, O 3 / R_{O H O 3}}$ values obtained for ozonized wastewater effluents. Correlation coefficients $\left(\mathrm{R}^{2}\right)$ greater than 0.98 were obtained in all cases. Discrepancies between coefficients values obtained in duplicate experiments were in all cases lower than $5 \%$.

\begin{tabular}{|c|c|c|c|c|c|c|c|c|}
\hline \multirow[t]{2}{*}{ WW ID } & \multicolumn{2}{|c|}{$\begin{array}{c}\mathbf{R}_{\mathrm{OHO3}} \\
{[\mathrm{s}]}\end{array}$} & \multicolumn{2}{|c|}{$\begin{array}{c}\mathbf{k}_{\mathrm{UVA}, \mathbf{O}} \\
{\left[\mathbf{M}^{-1}\right]}\end{array}$} & \multicolumn{2}{|c|}{$\begin{array}{c}\mathrm{k}_{\mathrm{UVA}, \mathrm{OH}} \\
\text { (experimental) } \\
{\left[\mathrm{M}^{-1} \mathbf{s}^{-1}\right]}\end{array}$} & \multicolumn{2}{|c|}{$\begin{array}{c}\mathbf{k}_{\mathrm{UVA}, \mathrm{OH}} \\
\left(\mathrm{k}_{\mathrm{UVA}, \mathbf{0 3}} / \mathbf{R}_{\mathrm{OHO3}}\right) \\
{\left[\mathbf{M}^{-1} \mathbf{s}^{-1}\right]}\end{array}$} \\
\hline & $\begin{array}{c}1^{\text {st }} \\
\left(\mathrm{x} 10^{7}\right)\end{array}$ & $\begin{array}{c}2^{\text {nd }} \\
\left(\times 10^{6}\right)\end{array}$ & $\begin{array}{c}1^{\text {st }} \\
\left(\times 10^{-3}\right)\end{array}$ & $\begin{array}{c}2^{\text {nd }} \\
\left(\times 10^{-3}\right)\end{array}$ & $\begin{array}{c}1^{\text {st }} \\
\left(\times 10^{-9}\right)\end{array}$ & $\begin{array}{c}2^{\text {nd }} \\
\left(\times 10^{-8}\right)\end{array}$ & $\begin{array}{c}1^{\text {st }} \\
\left(\times 10^{-9}\right)\end{array}$ & $\begin{array}{c}2^{\text {nd }} \\
\left(\times 10^{-8}\right)\end{array}$ \\
\hline M-VAC & 2.95 & 2.53 & 1.64 & 1.50 & 5.73 & 5.90 & 5.56 & 5.92 \\
\hline M-VAL & 7.60 & 2.95 & 2.59 & 1.79 & 3.37 & 6.06 & 3.41 & 6.05 \\
\hline M-GAV & 5.29 & 1.35 & 1.88 & 0.82 & 3.49 & 5.98 & 3.55 & 6.08 \\
\hline C-PRA & 2.94 & 1.18 & 1.48 & 0.76 & 4.94 & 6.46 & 5.03 & 6.43 \\
\hline C-GAV & 1.53 & 0.61 & 0.77 & 0.25 & 5.00 & 4.20 & 5.05 & 4.09 \\
\hline C-LLA & 1.79 & 1.23 & 0.93 & 0.59 & 5.13 & 4.80 & 5.20 & 4.80 \\
\hline
\end{tabular}

Changes in ozone transfer regimes turned into ca. 3 to 9-fold $\mathrm{ROHO}_{\mathrm{O}}$ increases between primary and secondary ozonation stages, depending on the water source. The observed trend in initial $\mathrm{R}_{\mathrm{OHO}}$ values were $\mathrm{M}-\mathrm{VAL}>\mathrm{M}-\mathrm{GAV}>\mathrm{M}-\mathrm{VAC} \approx \mathrm{C}-\mathrm{PRA}>\mathrm{C}-\mathrm{LLA}>\mathrm{C}-$ GAV. Although M-GAV and C-PRA exhibited similar values for $\bullet \mathrm{OH}$ exposure, the CPRA effluent had larger ozone needs caused by a higher content in organic matter and EfOM aromaticity. Therefore, for equal $\int[\bullet \mathrm{OH}] \mathrm{d} t$ values the M-GAV sample presented a better oxidation efficiency. Similarly, the obtained $R_{О Н О 3}$ values for M-VAC and C-PRA effluents were very close. The M-VAC effluent presents a $\mathrm{NO}_{2}{ }^{-}$content and alkalinity of $0.85 \mathrm{mg} \mathrm{N} \mathrm{L}^{-1}$ and $329.5 \mathrm{mg} \mathrm{CaCO}_{3} \mathrm{~L}^{-1}$, respectively, versus the $0.09 \mathrm{mg} \mathrm{N} \mathrm{L}^{-1}$ and 263.5 
mg $\mathrm{CaCO}_{3} \mathrm{~L}^{-1}$ exhibited by the C-PRA sample. Thus, differences in OM content between these two waters [M-VAC (TOC: $6.7 \mathrm{mg} \mathrm{L}^{-1}$ ), C-PRA (TOC: $14.0 \mathrm{mg} \mathrm{L}^{-1}$ )], were compensated by a larger $\mathrm{O}_{3}$ consumption without $\bullet \mathrm{OH}$ generation (nitrite) and also a higher $\bullet \mathrm{OH}$ scavenging rate (carbonates) in the case of the M-VAC effluent. M-VAL, CGAV and C-LLA effluents presented the highest and the two lowest oxidation efficiencies, respectively, which could be also explained by their relative water qualities: the M-VAL sample had relatively low values TOC and alkalinity, whereas the opposite situation was observed for C-GAV and C-LLA effluents.

\subsection{Effluent organic matter transformation during wastewater ozonation: evolution of $U V_{254}$ absorbance}

The absorbance spectra as a function of the transferred ozone dose (TOD) revealed a proportional decay in the UV absorption of the water throughout the entire ozonation time, at practically any of the studied wavelengths and for all the ozonized effluents (Fig. S6 of the SI). As known, the electron-rich moieties present in wastewater effluents (EfOM), with typically strong UV absorptions (von Sonntag and von Gunten, 2012), are certainly reactive to ozone: a sustained decrease in the UV absorption was therefore expected during the ozonation process. Fig. 4 shows, for all the tested effluents, the plot of the relative decrease in UV absorbance with time (A), as well as negative, natural logarithm of the relative UV absorbance versus the consumed ozone (B), represented in this case by the TOD. A wavelength of $254 \mathrm{~nm}$ was chosen for absorbance monitoring since $\mathrm{UVA}_{254}$ is one of the parameters typically monitored in practice. 


$$
-\ln \left(\frac{U V A_{254}}{U V A_{254,0}}\right)=k_{U V A, O 3} \cdot T O D
$$

The relationship between the absorbance decrease and the TOD is expressed by Eq. 5 . This is reasonable here since the decay of $\mathrm{UVA}_{254}$ has been demonstrated to follow a firstorder kinetic relationship with respect to ozone, and the ozone exposure (i.e., the timeintegrated $\mathrm{O}_{3}$ concentration) is directly proportional to the consumed dose of this oxidant (Buffle et al., 2006). In the view of the obtained results (Fig. 4B), in which linear relationships with regression coefficients greater than 0.98 were generally obtained, these assumptions were confirmed. 


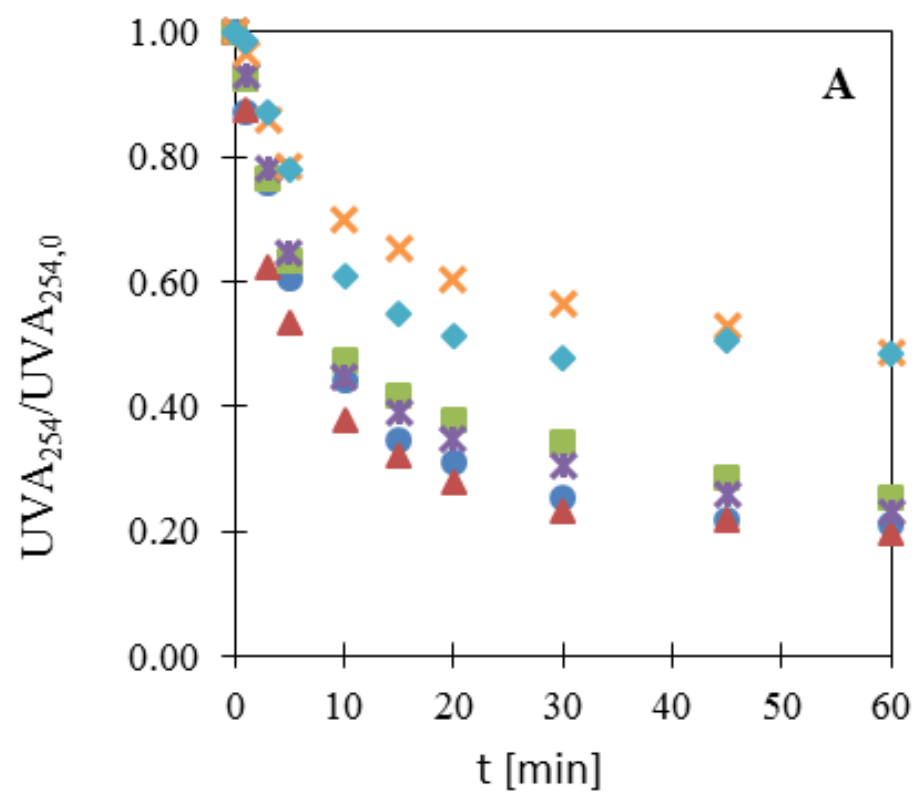

M-VAC $\triangle \mathrm{M}$-VAL $\square \mathrm{M}-\mathrm{GAV}$ ※C-PRA $\times \mathrm{C}$-GAV $\bullet \mathrm{C}-\mathrm{LLA}$

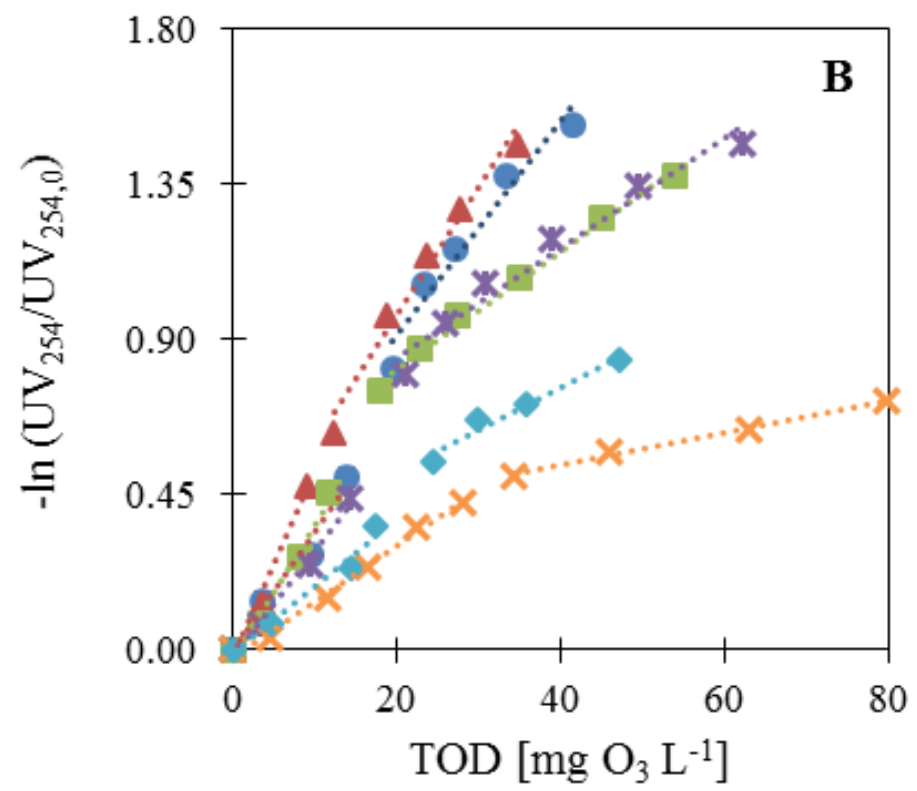

Figure 4. Changes in UV absorbance during ozonation of wastewater effluents. $\mathrm{UVA}_{254}$ evolution with time (A) and logarithmic relative decrease in $\mathrm{UVA}_{254}$ (B) as a function of the transferred ozone dose (TOD).

Again, two different regimes were observed regarding the rate of $\mathrm{UVA}_{254}$ reduction $\left(k_{U V A, O 3,}\right.$ Table 3$)$ in accordance with the relative amount of aromatic and unsaturated moieties contained in the EfOM along ozonation, for each one. M-VAL wastewater effluent exhibited the highest rate constant for $\mathrm{UVA}_{254}$ depletion $\left(2.59 \cdot 10^{3} \mathrm{M}^{-1}\right)$, whereas 
for the C-GAV effluent $\left(0.77 \cdot 10^{3} \mathrm{M}^{-1}\right)$ resulted to be the lowest one. This approximately 4-fold factor is partly explained by the huge differences found in particulate/colloidal organic matter content of the CAS effluent with respect to the MBR effluent, (see turbidity, TOC and DOC values in Table 1) (Marce et al., 2016). If the focus is put in waters in which less or no solids were present (M-VAL, M-VAC, M-GAV and C-PRA), other water quality parameters with high influence on the ozonation process, such as the carbonate presence (alkalinity) or the EfOM aromaticity can play an important role. So, the MBR effluent with the fastest kinetics (M-VAL) is also the one with a lower carbonate alkalinity content $\left(178 \mathrm{mg} \mathrm{CaCO}_{3} \mathrm{~L}^{-1}\right)$. $\bullet \mathrm{OH}$ oxidation appears to play a significant role in the $\mathrm{UVA}_{254}$ reduction process during ozonation, and a significant increase in the carbonate content reduces this important contribution by means of the scavenging effect.

\subsection{Kinetic modelling using the $R_{\mathrm{OHO}_{3}}$ concept and $U V A_{254}$ monitoring}

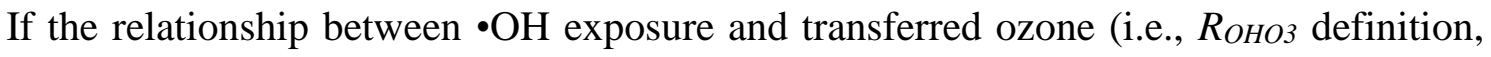
Eq. 3) and the relationship between $\mathrm{UVA}_{254}$ decay and TOD (Eq. 5) are both combined, a new expression relating the absorbance decrease and the $\bullet \mathrm{OH}$ exposure can be obtained (Eq. 6).

$$
-\ln \left(\frac{U V A_{254}}{U V A_{254,0}}\right)=k_{U V A, O H} \cdot \int[\bullet O H] \mathrm{d} t
$$

Therefore, if the logarithm of the relative measured $\mathrm{UVA}_{254}$ is graphically represented against the time-integrated hydroxyl radical concentration, a linear correlation is expected. Fig. 5 shows the logarithm of relative $\mathrm{UVA}_{254}$ as a function of the hydroxyl radical exposure, determined for all the tested effluents. Experimental data were fitted by 
straight lines $\left(\mathrm{R}^{2}>0.98\right)$, thus confirming the linear behavior for this data set previously deduced by means of theoretical analysis. Obtained $k_{U V A, O H}$ values, that is, the slope of the obtained linear relationship described by Eq. 6, are gathered in Table 3. To further validate the relationship obtained by the combination of Eqs. 2 and 4, $k_{U V A, O H}$ calculated as $k_{U V A, O 3} / R_{O H O 3}$ was also included in this table and compared with the experimentally determined values, obtaining differences ranging from 0.1 to $3.0 \%$.

According to the obtained results, good correlations could be established between $\cdot \mathrm{OH}-$ exposure and $\mathrm{UVA}_{254}$ attenuation, which opens the door to potential real-time estimations of the $\int[\bullet \mathrm{OH}] \mathrm{d} t$ term by means of online $\mathrm{UVA}_{254}$ measurements. The use of a similar approach has been recently reported by Chys et al., who obtained good correlations between $\cdot \mathrm{OH}$-exposure and both $\mathrm{UVA}_{254}$ and $\mathrm{TF}$ attenuation $\left(\mathrm{R}^{2}\right.$ in the range of 0.82 0.90) in lab-scale wastewater ozonation experiments. Similarly to $R_{O H O 3}$ concept, initial $k_{U V A, O H}$ values obtained in the present study would be useful to perform $\bullet \mathrm{OH}$-exposure estimations during the primary ozonation stage, that is, if working ozone doses are within IOD completion. That situation, as mentioned, would represent typical operational conditions of actual ozone applications for enhanced water and wastewater treatment. However, if ozonation is wanted to be extended up to the application of $\mathrm{O}_{3}$ doses beyond IOD, the second-stage $k_{U V A, O H}$ value should be used for $\bullet \mathrm{OH}$-exposure predictions in the secondary ozonation stage. By means of these two values, therefore, a complete characterization of the radical availability during the whole ozonation process is certainly possible. 

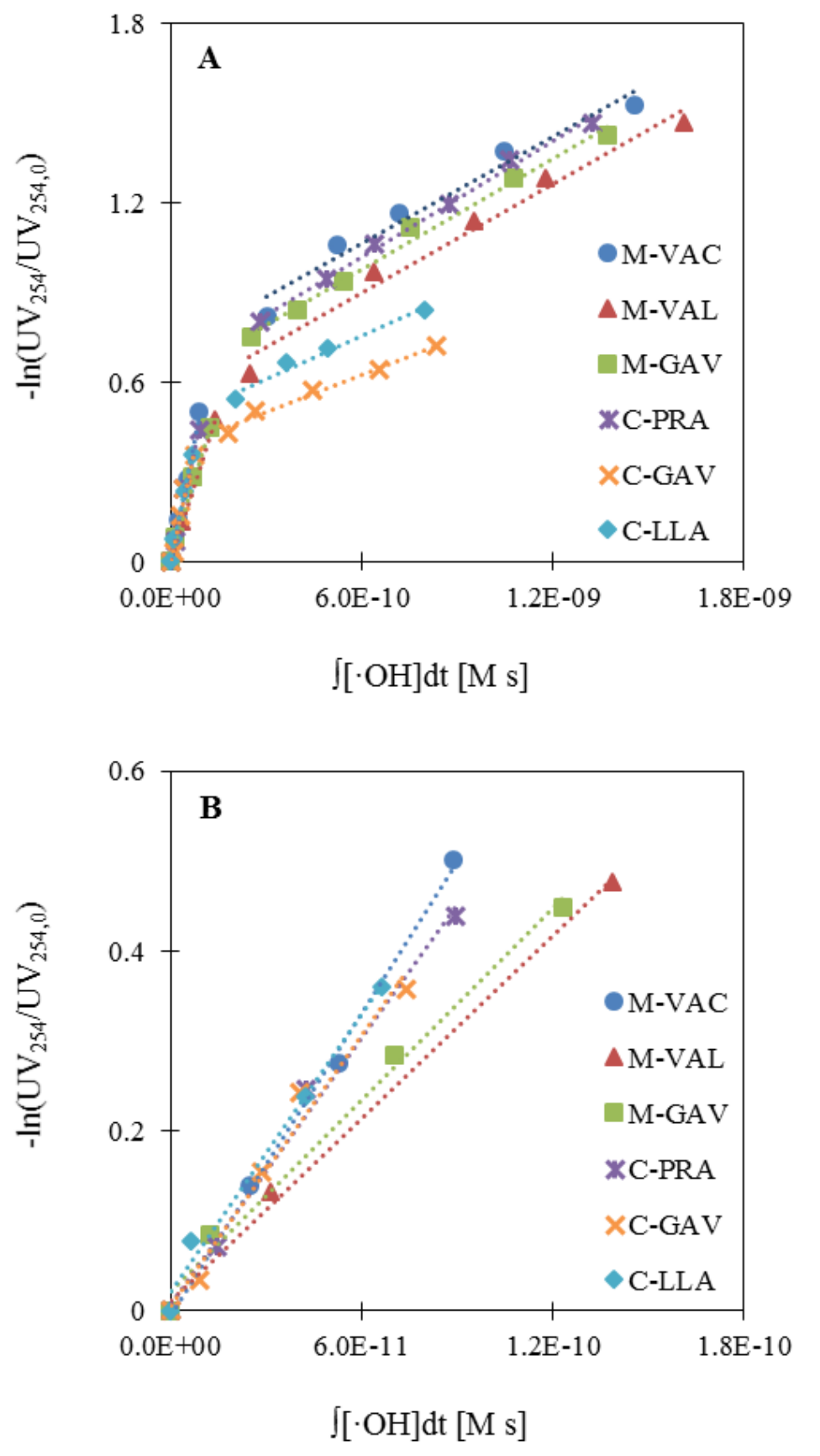

Figure 5. Natural logarithm of relative $\mathrm{UVA}_{254}$ as a function of $\bullet \mathrm{OH}$ exposure, determined during ozonation experiments of different wastewater effluent samples: A, entire ozonation time; B, zoom of data corresponding to initial ozonation stage.

It seems to be that even a general model for $\cdot \mathrm{OH}$-exposure prediction by $\mathrm{UVA}_{254}$ measurements could be proposed for clearer effluents such as membrane bioreactor effluents and C-PRA $\left(\mathrm{R}^{2}=0.94\right.$ and 0.92 for initial and secondary ozonation stages, 
respectively, see SI-Fig. S7). Significant deviations from these predictions, however, would be observed for CAS effluents with relatively high content in OM and inorganic salts (i.e., C-GAV and C-LLA samples). Further investigations, therefore, would be required in these cases to accurately quantify the individual and synergistic effects exerted by main matrix components, so proper corrections according to the water quality could be applied to the model.

3.5. Prediction of ozone-resistant micropollutants removal by means of models based on $R_{O H O 3}$ and $U V A_{254}$ measurements

In order to evaluate the usefulness of both the $\mathrm{ROHO}_{\mathrm{O}}$ concept and the newly developed method for $\cdot \mathrm{OH}$ exposure monitoring by means of $\mathrm{UVA}_{254}$ measurements, removal prediction assays were conducted for each wastewater effluent and two typical target compounds: ibuprofen (IBU) and atrazine (ATZ). The deprotonated form of both chemicals, predominant at neutral $\mathrm{pH}$, present low reactivity towards ozone, with secondorder rate constants of 9.6 and $6 \mathrm{M}^{-1} \mathrm{~s}^{-1}$, respectively, and moderate/high reactivity with hydroxyl radicals $\left(k \cdot O H\right.$ of $7.4 \cdot 10^{9}$ and $3.0 \cdot 10^{9} \mathrm{M}^{-1} \mathrm{~s}^{-1}$ for IBU and ATZ, respectively) (Acero et al., 2000; Huber et al., 2003). According to Eq. 2 and both the $R_{O H O 3}$ and $k_{U V A, O 3}$ definitions (Eqs. 3 and 5), the removal of these two $\mathrm{O}_{3}$-resistant micropollutants (MPs) can be predicted by Eqs. 7 and 8, respectively.

$$
-\ln \left(\frac{[M P]}{[M P]_{0}}\right)=k_{\bullet O H} \cdot R_{O H O 3} \cdot T O D
$$




$$
-\ln \left(\frac{[M P]}{[M P]_{0}}\right)=k_{\bullet O H} \cdot \frac{-\ln \left(\frac{U V A_{254}}{U V A_{254,0}}\right)}{k_{U V A, O H}}
$$

Consistently with the work developed in this study, and according to the fact that we extended ozonation experiments in order to achieve the complete abatement of ozonerecalcitrant micropollutants, two-phase models were employed for these calculations using the $\mathrm{ROHO}_{\mathrm{OH}}$ and $k_{U V A, O 3}$ values determined in primary and secondary ozonation stages, for each tested water source.
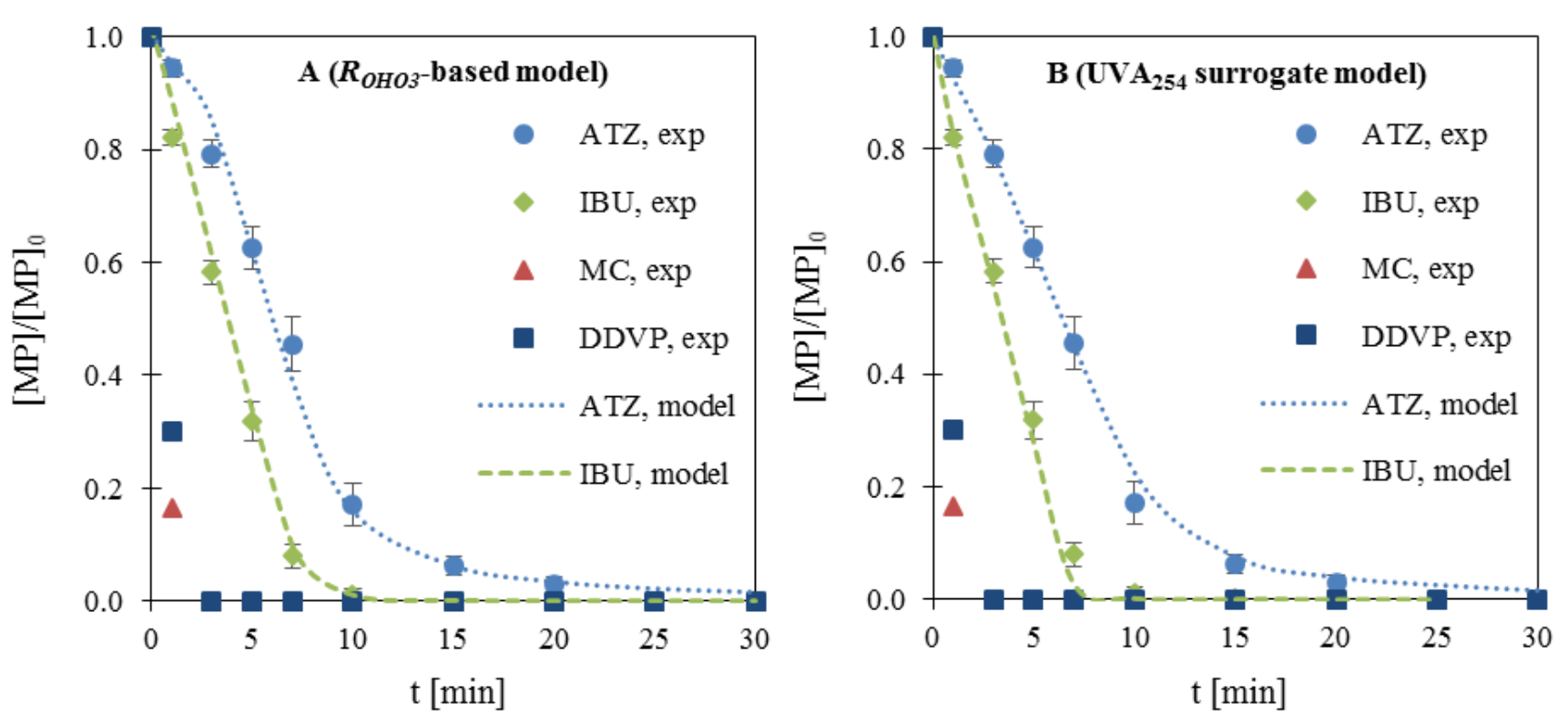

Figure 6. Prediction of ATZ and IBU removals during ozonation of M-VAC (representative example) effluent, employing both the $\mathrm{R}_{\mathrm{OHO}}$ concept (A) and the $\mathrm{UVA}_{254}$-based strategy for $\bullet \mathrm{OH}$ exposure prediction (B). $[\mathrm{ATZ}]_{0}=[\mathrm{IBU}]_{0}=25 \mu \mathrm{g} \mathrm{L}{ }^{-1},[\mathrm{MC}]_{0}=[\mathrm{DDVP}]_{0}=50 \mu \mathrm{g} \mathrm{L}-1$; Gas flow rate $=0.100 \pm 0.005 \mathrm{NL} \mathrm{min}^{-1}$; Inlet (gas) ozone concentration $=30 \pm 1 \mathrm{mg} \mathrm{O}_{3} \mathrm{NL}^{-1} ; \mathrm{T}_{\text {reaction }}=20 \pm 1{ }^{\circ} \mathrm{C}, \mathrm{T}_{\text {in }}$ (gas) $=22 \pm 2{ }^{\circ} \mathrm{C} ; \mathrm{P}_{\text {in }}$ (gas) $=$ $25 \pm 2$ mbar.

Fig. 6 shows the removal profiles of ATZ and IBU predicted for the M-VAC effluent, as representative example, together with the relative residual concentrations experimentally 
determined during the tests. The concentrations of two additional micropollutants, the pesticides methiocarb (MC) and dichlorvos (DDVP), were also followed during removal prediction tests. $\mathrm{MC}$ presents high reactivity towards both $\mathrm{O}_{3}$ and $\bullet \mathrm{OH}\left(k_{M C, O 3}=1.7 \cdot 10^{6}\right.$ $\mathrm{M}^{-1} \mathrm{~s}^{-1}$ and $k_{M C} \cdot O H=8.2 \cdot 10^{9} \mathrm{M}^{-1} \mathrm{~s}^{-1}$, (Cruz-Alcalde et al., 2017b)), whereas the insecticide DDVP rapidly reacts with hydroxyl radical but has a moderate reaction rate with ozone $\left(k_{D D V P, O 3}=590 \mathrm{M}^{-1} \mathrm{~s}^{-1}\right.$ and $k_{D D V P, O H}=2.2 \cdot 10^{9} \mathrm{M}^{-1} \mathrm{~s}^{-1}$, (Cruz-Alcalde et al., 2018) $)$. Similar plots were obtained for the rest of tested effluent samples (see SI, Figs. S8 and S9). In all cases, a good agreement between model predictions and experimental measurements was observed. An initial, rapid removal rate followed by a slower degradation period was observed for ATZ and IBU, being the depletion of ATZ always less efficient than that for IBU. This was kinetically consistent, as IBU presents lower rate constant with $\bullet \mathrm{OH}$ than ATZ. On the other hand, MC and DDVP pesticides were degraded below their respective detection limits at a contact time less than $5 \mathrm{~min}$. These results highlight again the strong dependence between the removal of micropollutants with low ozone reactivity and $\bullet \mathrm{OH}$ exposure, which in turn can represent a limiting factor when implementing ozonation treatments in secondary effluents. Chemicals with significant ozone reactivity here illustrated by the MC and DDVP examples in this work are always faster eliminated by the contribution of direct ozonation. Finally, Fig. 7 shows how the removal of IBU and ATZ could be accurately predicted by employing both ROHO3 $_{O}$ and $k_{U V A, O H}$ concepts along with chemical kinetics, in a wide range of wastewater effluent qualities $\left(R^{2}>0.98\right.$ for both models), down to complete recalcitrant micropollutants abatement. 

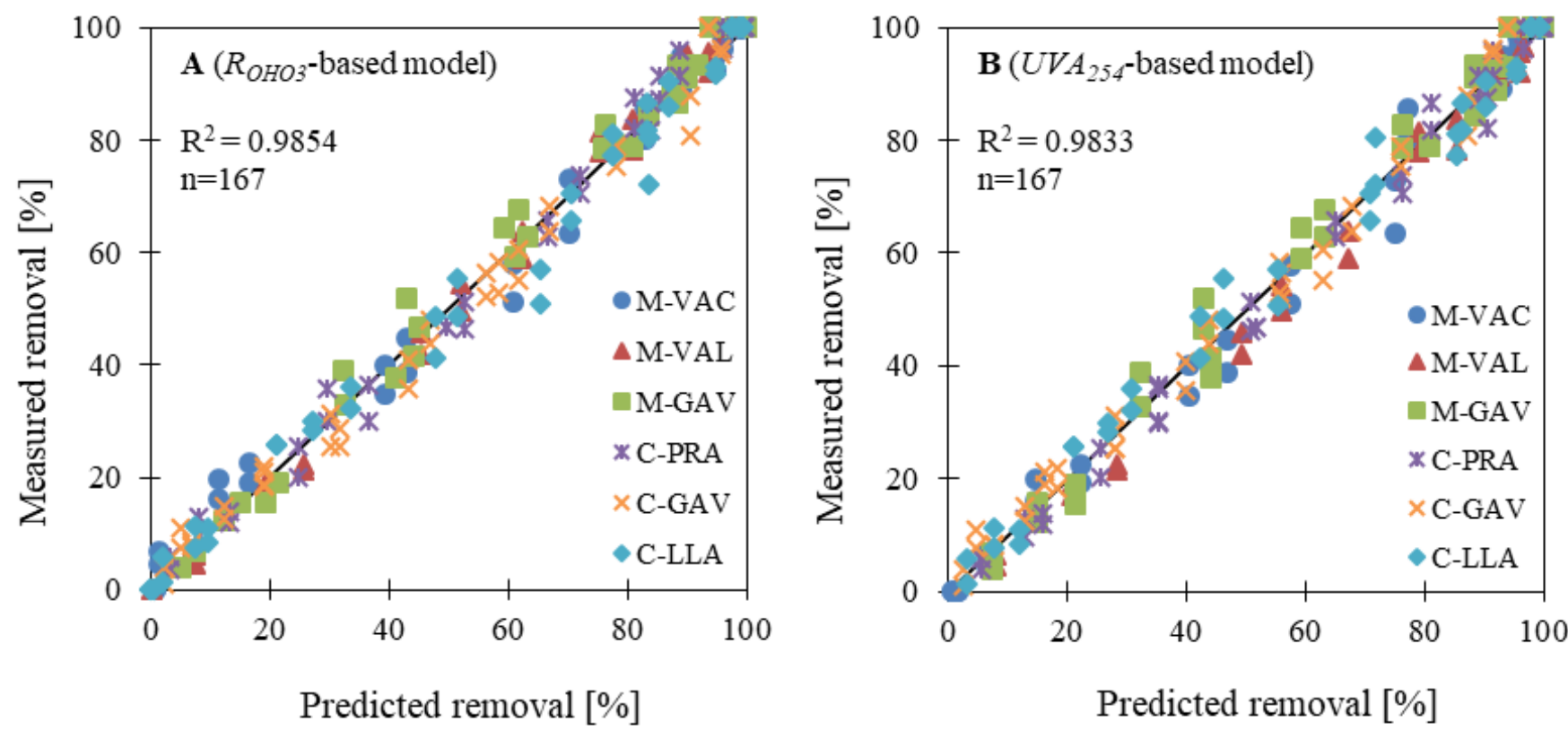

Figure 7. Measured versus predicted removals for atrazine and ibuprofen in six different wastewater effluents, employing both $R_{О Н О 3}(\mathrm{~A})$ and $U V A_{254}$-based (B) models.

\section{Conclusions}

The production of a high quality reclaimed wastewater, especially if the final application of this water involves potential human exposure, may require the monitoring and control of ozone-resistant micropollutants from wastewater effluents. In this work, the oxidation performance of the whole semi-continuous ozonation process could be well described by means of a two-stage model based on $\mathrm{ROHO}_{\mathrm{OH}}$ concept. Determining the $\mathrm{ROHO}_{\mathrm{O}}$ values necessary to describe both initial and secondary ozonation stages was achieved by coupling chemical kinetics with a proper assessment of the ozone mass transfer. This tool was demonstrated to be useful to describe and compare the process in different effluents showing a broad range of water properties. By means of this approach, hydroxyl radical exposures during ozonation could be accurately determined during the whole treatment, provided that the consumed ozone dose was always known. Also derived from a strategy 
based on the $R_{\text {OHO3 }}$ concept, a new model involving $\mathrm{UVA}_{254}$ monitoring was proposed for the online estimation of hydroxyl radical exposure along the entire process. The fundamentals of a potential strategy for the monitoring and control of ozone-recalcitrant micropollutants abatement during ozonation have been developed and presented in this paper. Further research in this direction is from now on required, including exhaustive studies concerning the influence of water quality and seasonal variations on the kinetic parameters of the model (i.e., $R_{\mathrm{OHO}}$ and $\left.k_{U V A, \mathrm{OH}}\right)$.

\section{Acknowledgements}

This work was financially supported by the Spanish Ministry of Economy and Competitiveness (project CTQ2017-86466-R and Alberto Cruz's FPI fellowship BES2015-074109) and the Agency for Management of University and Research Grants of the Government of Catalonia (project 2017SGR131).

\section{References}

Acero, J.L., Stemmler, K., Von Gunten, U., 2000. Degradation kinetics of atrazine and its degradation products with ozone and $\mathrm{OH}$ radicals: A predictive tool for drinking water treatment. Environ. Sci. Technol. 34, 591-597. https://doi.org/10.1021/es990724e

Bourgin, M., Beck, B., Boehler, M., Borowska, E., Fleiner, J., Salhi, E., Teichler, R., von Gunten, U., Siegrist, H., McArdell, C.S., 2018. Evaluation of a full-scale wastewater treatment plant upgraded with ozonation and biological post-treatments: Abatement of micropollutants, formation of transformation products and oxidation by-products. 
Water Res. 129, 486-498. https://doi.org/10.1016/J.WATRES.2017.10.036

Buffle, M.O., Schumacher, J., Meylan, S., Jekel, M., Von Gunten, U., 2006. Ozonation and advanced oxidation of wastewater: Effect of $\mathrm{O} 3$ dose, pH, DOM and HO.scavengers on ozone decomposition and HO . generation. Ozone Sci. Eng. 28, 247259. https://doi.org/10.1080/01919510600718825

Buxton, G. V, Greenstock, C.L., Helman, W.P., Ross, A.B., 1988. Critical Review of rate constants for reactions of hydrated electrons, hydrogen atoms and hydroxyl radicals in aqueous solution. J. Phys. Chem. Ref. Data 17, 513. https://doi.org/10.1063/1.555805

Chys, M., Audenaert, W.T.M., Deniere, E., Mortier, S.T.F.C., Van Langenhove, H., Nopens, I., Demeestere, K., Van Hulle, S.W.H., 2017. Surrogate-Based Correlation Models in View of Real-Time Control of Ozonation of Secondary Treated Municipal Wastewater-Model Development and Dynamic Validation. Environ. Sci. Technol. 51, 14233-14243. https://doi.org/10.1021/acs.est.7b04905

Cruz-Alcalde, A., Sans, C., Esplugas, S., 2018. Priority pesticide dichlorvos removal from water by ozonation process: Reactivity, transformation products and associated toxicity. Sep. Purif. Technol. 192, 123-129. https://doi.org/10.1016/j.seppur.2017.09.069

Cruz-Alcalde, A., Sans, C., Esplugas, S., 2017a. Priority pesticides abatement by advanced water technologies: The case of acetamiprid removal by ozonation. Sci. Total Environ. 599-600, $1454-1461$. https://doi.org/10.1016/j.scitotenv.2017.05.065

Cruz-Alcalde, A., Sans, C., Esplugas, S., 2017b. Exploring ozonation as treatment alternative for methiocarb and formed transformation products abatement. Chemosphere 186, 725-732. https://doi.org/10.1016/j.chemosphere.2017.08.040 
Drewes, J.E., Anderson, P., Denslow, N., Olivieri, A., Schlenk, D., Snyder, S.A., Maruya, K.A., 2013. Designing monitoring programs for chemicals of emerging concern in potable reuse ??? What to include and what not to include? Water Sci. Technol. 67, 433-439. https://doi.org/10.2166/wst.2012.520

Elovitz, M.S., Von Gunten, U., 1999. Hydroxyl Radical/Ozone Ratios During Ozonation Processes. I. The Rct Concept. Ozone Sci. Eng. 21, 239-260. https://doi.org/10.1080/01919519908547239

Gerrity, D., Gamage, S., Holady, J.C., Mawhinney, D.B., Quiñones, O., Trenholm, R.A., Snyder, S.A., 2011. Pilot-scale evaluation of ozone and biological activated carbon for trace organic contaminant mitigation and disinfection. Water Res. 45, 21552165. https://doi.org/10.1016/j.watres.2010.12.031

Gerrity, D., Gamage, S., Jones, D., Korshin, G. V., Lee, Y., Pisarenko, A., Trenholm, R.A., von Gunten, U., Wert, E.C., Snyder, S.A., 2012. Development of surrogate correlation models to predict trace organic contaminant oxidation and microbial inactivation during ozonation. Water Res. 46, 6257-6272. https://doi.org/10.1016/j.watres.2012.08.037

Huber, M.M., Canonica, S., Park, G.Y., Von Gunten, U., 2003. Oxidation of pharmaceuticals during ozonation and advanced oxidation processes. Environ. Sci. Technol. 37, 1016-1024. https://doi.org/10.1021/es025896h

Jiang, P., Chen, H.-T., Babcock, R.W., Stenstrom, M.K., 2009. Modeling ozone mass transfer in reclaimed wastewater. Water Environ. Res. a Res. Publ. Water Environ. Fed. 81, 57-68. https://doi.org/10.2175/106143008X325782

Kwon, M., Kye, H., Jung, Y., Yoon, Y., Kang, J.-W., 2017. Performance characterization and kinetic modeling of ozonation using a new method: $\mathrm{R} \mathrm{OH}, \mathrm{O} 3$ concept. Water Res. 122, 172-182. https://doi.org/10.1016/j.watres.2017.05.062 
Lee, Y., Gerrity, D., Lee, M., Bogeat, A.E., Salhi, E., Gamage, S., Trenholm, R.A., Wert, E.C., Snyder, S.A., Von Gunten, U., 2013. Prediction of micropollutant elimination during ozonation of municipal wastewater effluents: Use of kinetic and water specific information. Environ. Sci. Technol. 47, 5872-5881. https://doi.org/10.1021/es400781r

Lee, Y., Kovalova, L., McArdell, C.S., von Gunten, U., 2014. Prediction of micropollutant elimination during ozonation of a hospital wastewater effluent. Water Res. 64, 134-148. https://doi.org/10.1016/j.watres.2014.06.027

Levenspiel, O., 1999. Chemical reaction engineering, 3rd ed, Ind. Eng. Chem. Res. John Willey \& Sons. https://doi.org/10.1021/ie990488g

Marce, M., Domenjoud, B., Esplugas, S., Baig, S., 2016. Ozonation treatment of urban primary and biotreated wastewaters: Impacts and modeling. Chem. Eng. J. 283, 768777. https://doi.org/10.1016/j.cej.2015.07.073

Nakada, N., Shinohara, H., Murata, A., Kiri, K., Managaki, S., Sato, N., Takada, H., 2007. Removal of selected pharmaceuticals and personal care products (PPCPs) and endocrine-disrupting chemicals (EDCs) during sand filtration and ozonation at a municipal sewage treatment plant. Water Res. 41, 4373-4382. https://doi.org/10.1016/j.watres.2007.06.038

Naumov, S., Mark, G., Jarocki, A., von Sonntag, C., 2010. The Reactions of Nitrite Ion with Ozone in Aqueous Solution - New Experimental Data and Quantum-Chemical Considerations. Ozone Sci. Eng. 32, 430-434. https://doi.org/10.1080/01919512.2010.522960

Oulton, R.L., Kohn, T., Cwiertny, D.M., 2010. Pharmaceuticals and personal care products in effluent matrices: A survey of transformation and removal during wastewater treatment and implications for wastewater management. J. Environ. 
Monit. 12, 1956. https://doi.org/10.1039/c0em00068j

Park, M., Anumol, T., Daniels, K.D., Wu, S., Ziska, A.D., Snyder, S.A., 2017. Predicting trace organic compound attenuation by ozone oxidation: Development of indicator and surrogate models. Water Res. 119, 21-32. https://doi.org/10.1016/j.watres.2017.04.024

Reungoat, J., Escher, B.I., Macova, M., Argaud, F.X., Gernjak, W., Keller, J., 2012. Ozonation and biological activated carbon filtration of wastewater treatment plant effluents. Water Res. 46, 863-872. https://doi.org/10.1016/j.watres.2011.11.064

Schindler Wildhaber, Y., Mestankova, H., Schärer, M., Schirmer, K., Salhi, E., von Gunten, U., 2015. Novel test procedure to evaluate the treatability of wastewater with ozone. Water Res. 75, 324-335. https://doi.org/10.1016/j.watres.2015.02.030

Stapf, M., Miehe, U., Jekel, M., 2016. Application of online UV absorption measurements for ozone process control in secondary effluent with variable nitrite concentration. Water Res. 104, 111-118. https://doi.org/10.1016/j.watres.2016.08.010 von Sonntag, C., von Gunten, U., 2012. Chemistry of Ozone in Water and Wastewater Treatment: From Basic Principles to Applications. IWA Publishing.

Zimmermann, S.G., Wittenwiler, M., Hollender, J., Krauss, M., Ort, C., Siegrist, H., von Gunten, U., 2011. Kinetic assessment and modeling of an ozonation step for fullscale municipal wastewater treatment: Micropollutant oxidation, by-product formation and disinfection. Water Res. 45, 605-617. https://doi.org/10.1016/j.watres.2010.07.080 